\title{
Actualidad del Tratamiento Renal Sustitutivo Pediátrico
}

\author{
Dolores Andreu Periz, José Antonio Sarria \\ Facultad de Medicina y Ciencias de la Salud. Universitat de Barcelona. España
}

Son escasos los datos sobre la incidencia de ERC en los niños y es posible que esté subestimada pues en muchos casos los estadios iniciales no se diagnostican. Los registros europeos muestran en esta población una prevalencia de entre 59-74 por millón de población y el Registro Español Pediátrico de ERC no terminal (REPIR II), que recoge estadios más tempranos, encontró una prevalencia superior a 128 por millón de población. La enfermedad es más frecuente en varones y la causa principal las anomalías estructurales ${ }^{1,2}$.

El paciente renal pediátrico necesita de un seguimiento riguroso por equipos especializados que traten precozmente las alteraciones que se producen en su metabolismo y crecimiento. El control de la enfermedad mineral ósea, de la anemia y del crecimiento se ha de complementar con la intervención nutricional puesto que la malnutrición es muy frecuente, todo ello requiere del seguimiento por unidades especializadas ${ }^{3}$.

Si pese a esta atención la enfermedad aboca a alguno de estos niños a necesitar de tratamiento sustitutivo se plantea elegir la técnica más adecuada que pasará por siempre por considerar el trasplante renal de donante vivo como la mejor opción terapéutica. Este trasplante no solo evita la diálisis, al aportar una buena masa renal con mínimo tiempo de isquemia fría, también ofrece una mejor supervivencia del injerto, con poca inmunosupresión, mejora el crecimiento y puede proporcionar buena calidad de vida ${ }^{2}$. Suele ha-

Correspondencia:

Dolores Andreu Periz

Universitat de Barcelona.Departamento de Enfermería Fundamental y Medicoquirúrgica

C/ Feixa Llarga. s/n

08907 L'Hospitalet de Llobregat. Barcelona. España

E-mail:Iolaandreu@ub.edu ber buenas opciones de donación por parte de los padres que además suelen ser compatibles. Actualmente, el trasplante con padres no compatibles o los programas de donante cruzado han aumentado las posibilidades de poder trasplantar a los niños. Las técnicas de diálisis y el control de la enfermedad de base están permitiendo a niños muy pequeños alcanzar el crecimiento necesario para recibir un trasplante. Son tratamientos altamente especializados y deben llevarse a cabo en unidades con dotaciones multidisciplinares específicas y siempre bajo la supervisión de un nefrólogo pediatra².

Si el trasplante de donante vivo no puede realizarse por el comienzo agudo de la enfermedad, por la edad muy temprana del niño o por otra causa, la elección de la técnica depuradora ha de tener en cuenta varios factores aunque, en general, la diálisis peritoneal es la más habitual en todos los países. En España, constituye la modalidad de tratamiento inicial más común en menores de 6 años y en una tercera parte de todos los menores de 18 años ${ }^{3}$.

La diálisis peritoneal está indicada en cualquier niño pero resulta especialmente útil para los más pequeños y con dificultades en el acceso vascular. Como en los adultos, las técnicas automáticas ofrecen muchas ventajas y los beneficios del tratamiento dependen en gran medida del buen funcionamiento del catéter y por tanto son fundamentales la técnica de inserción y los cuidados para mantenerlo. Además de criterios de calidad como el aclaramiento y la ultrafiltración es necesario contemplar un adecuado crecimiento y buena integración escolar y social ${ }^{3,4}$.

Si la técnica elegida es la hemodiálisis se ha de tener en cuenta además de las grandes diferencias en el peso, que los niños muestran características particulares por lo que hay grandes diferencias en cuanto a los adultos respecto a materiales, parámetros y otras consideraciones que requieren de una formación específica para los profesionales que les atienden ${ }^{5}$. 
Los avances en las técnicas depuradoras y en el trasplante renal han incrementado la supervivencia de niños con enfermedad renal. Incluso los lactantes y neonatos con enfermedad renal sin comorbilidades añadidas tiene buen pronóstico. Se asocia a mayor mortalidad, la corta edad de inicio del tratamiento renal sustitutivo, la patología no renal, el prolongado tiempo en diálisis y la enfermedad cardiovascular².

Los profesionales de enfermería que atienden a pacientes renales pediátricos se enfrentan a múltiples retos que incluyen estar al día en aspectos como resultados de las diferentes formas de tratamiento renal sustitutivo. En esta selección de artículos se plantea la importancia de favorecer el trasplante con donantes óptimos y se analizan trabajos sobre la atención pediátrica cuando es necesario recurrir a técnicas dialíticas.

\section{Keith DS, Vranic G, Barcia J, Norwood V, Nishio- Lucar. Longitudinal analysis of living donor kidney transplant rates in pediatric candidates in the United States. A.Pediatr Transplant. 2016 Dec 30. doi: 10.1111/petr.12859}

Para garantizar el éxito de los programas de trasplante los estados promueven normas reguladoras que implican la adecuada distribución de los órganos. En este sentido, la Organización de Trasplante de España es el mejor ejemplo a nivel mundial de su eficiencia. Es interesante ver como en otros países dichas normas reguladoras animan a los investigadores a analizar su impacto.

En este artículo los autores afirman que en Estados Unidos desde 2014 se está produciendo una disminución de las tasas de donación de vivo en adultos, y se preguntan si esto ocurre también en la donación para niños.

En este país se implementó en 2005 una nueva política federal sobre donación denominada Share 35 que influencia la donación de vivo. Esta norma (algo así como "compartir $35^{\prime \prime}$ ), ofrece preferentemente los riñones de donantes fallecidos menores de 35 años a los niños que necesitan un trasplante. El objetivo de este trabajo fue determinar si había una disminución de la donación en vivo para niños y si la Share 35 podría influir en las tasas de donación.

Con este fin se identificaron a todos los niños candidatos a recibir un trasplante entre 1996 y 2011 ( $N=14$ 911 ) de los cuales 6046 había recibido un trasplante de donante vivo durante este periodo. El análisis de Kaplan-Meier mostró una disminución en el número de donantes vivos después de 2001 . Por otra parte, el análisis de regresión logística de los donantes confirmó está caída pero también demostró que había cambios demográficos y otros criterios en el manejo de las listas de candidatos por parte de los centros que se relacionaban con dicha disminución, siendo la principal causa el menor número de donaciones por parte de los padres.

Como conclusión los autores apuntan que la tasa de donante vivo para pacientes pediátricos declinó cuatro años antes de la implementación de la Share 35, lo que sugiere que factores distintos a los que dicha norma regula son los responsables de dicha caída.

Este estudio confirma lo demostrado por otros autores respecto a la influencia de la Share 35 en los trasplantes pediátricos. Así, Amaral S, Patzer R, Kutner y McClellan W en un artículo titulado "Disparidades raciales en el acceso al trasplante pediátrico desde la Share 35", publicado en 2012 en el Journal of American Society of Nephrology, afirman que aunque han disminuido las disparidades raciales y se ha incrementado el número de trasplantes, ha disminuido la donación de vivo.

de Souza VC1, Rabilloud M, Cochat P, Wagner MB, García CD, Ranchin B, Iwaz J, Selistre L, Dubourg L. Trajectories and Predictors of Allograft Dysfunction after Renal Transplantation in Children. Am J Nephrol. 2017; 45(1):63-68. doi: 10.1159/000453076.

Los índices de supervivencia de los niños sometidos a un trasplante renal son cada vez mayores, por lo que es importante procurar que se mantenga en estos niños una función renal óptima conforme van creciendo y en etapas posteriores.

El número de nefronas útiles y la capacidad del injerto para adaptarse a una demanda cada vez mayor durante el desarrollo corporal son los factores más importantes para que la función del injerto sea la adecuada a largo plazo. Este estudio examina la evolución a largo plazo de la tasa de filtración glomerular en una cohorte de trasplantados de riñón pediátrico; tiene en cuenta la importancia de las edades del receptor y del donante en la predicción del resultado del trasplante.

Se analizaron los datos en 67 niños trasplantados renales entre 2000 y 2010 a los que se practicó aclaramientos de inulina. Mediante un modelo de clases latentes se identificaron las trayectorias de la fun- 
ción renal de los niños trasplantados clasificándola en tres categorías: "baja y decreciente", "moderada y estable" y "alta y marcadamente decreciente". La probabilidad de pertenecer a la categoría "trayectoria baja y decreciente" es decir, de tener los peores resultados, fue inferior en los receptores de los injertos de donantes vivos respecto al donante cadáver (odds ratio ajustado* ( $a 0 R$ ) 0,$02 ; p=0,03$ ). Esta probabilidad también aumenta con la edad del receptor (a0R 1.20 por año de envejecimiento del receptor; $p=0,07$ ) y con la diferencia de edad entre el donante y el receptor (aOR 1.13 anuales adicionales; $p=0,07$ ).

Los autores reafirman en sus conclusiones que la donación de vivos y de donantes más jóvenes son factores favorables para la función del injerto a largo plazo.

Ashkenazi-Hoffnung L1,2, Davidovits M3,2, Bilavsky E1,2, Yassin R2, Rom E1,2, Amir J1,2. Children after renal transplantation hospitalized for fever: Is empirical antibiotic treatment always justified?.Pediatr Transplant. 2017 Jan 2. doi: 10.1111/petr.12862.

Numerosas investigaciones demuestran que las infecciones son la principal causa de morbilidad y mortalidad tras un trasplante renal. No obstante hay pocos datos sobre estos problemas en niños trasplantados.

El objetivo de este grupo de investigadores de un hospital de Tel Aviv fue conocer la frecuencia y predictores de infección bacteriana en niños portadores de un injerto renal que habían sido ingresados en el hospital por fiebre.

En este estudio retrospectivo se consideraron datos clínicos y de laboratorio de todos los pacientes pediátricos trasplantados y hospitalizados por fiebre en el periodo comprendido entre 2004 y 2012. Se registraron 168 ingresos hospitalarios a 52 niños a los que se diagnosticó una etiología bacteriana en 85 ingresos; 49 casos se documentaron con análisis y 36 por la clínica. Los factores de riesgo que definieron la infección bacteriana incluyeron la edad, el ser portador de un catéter venoso, hallazgos sonográficos e índices de marcadores inflamatorios elevados. La proteína $C$ reactiva fue un marcador más sensible que el recuento de células blancas o de neutrófilos. En pacientes en los que no se encontraron factores de riesgo no se diagnosticaron infecciones bacterianas.
A la vista de estos resultados, los autores concluyen que pese al riesgo de bacteriemia que presentan los niños trasplantados que aconseja adminístrales un tratamiento empírico con antibióticos, existe una minoría de pacientes de bajo riesgo en los que los médicos pueden considerar la posibilidad de suspender el tratamiento con antibióticos siempre que se les haga un seguimiento cercano.

Vidal E, van Stralen KJ, Chesnaye NC, Bonthuis M, Holmberg C, Zurowska A, et ESPN/ERAEDTA Registry.Infants. Requiring Maintenance Dialysis: Outcomes of Hemodialysis and Peritoneal Dialysis. Am J Kidney Dis. 2016 Dec 9.: S0272-6386(16)30596-0. doi: 10.1053/j. ajkd.2016.09.024.

Este estudio multicéntrico pretende determinar el impacto de diferentes modalidades de diálisis sobre los resultados clínicos en los bebés con insuficiencia renal crónica.

Los datos se obtuvieron del registro ESPN/ERA-EDTA e incluyeron a 1.063 niños de 12 meses o menos que iniciaron terapia con diálisis entre 1991 y 2013.

Mediante análisis de regresión de Cox ajustando por edad al inicio de la terapia, sexo, enfermedad renal y país de residencia, se analizaron las diferencias entre los lactantes tratados con diálisis peritoneal o hemodiálisis en cuanto a su supervivencia, el tiempo de duración de la técnica y el acceso al trasplante.

Se trató con diálisis peritoneal a 917 niños y a 146 con hemodiálisis, la edad media al inicio de la terapia fue de 4.5 meses (rango intercuartil, 0,7- 7,9) y el peso corporal medio fue de $5,7 \mathrm{~kg}$ (rango intercuartil, 3.7-7.5). Aunque los grupos eran homogéneos en cuanto a edad y sexo, los recién nacidos tratados con diálisis peritoneal tenían más anomalías congénitas del riñón y del tracto urinario ( $48 \%$ vs $27 \%$ ), mientras que los sometidos a hemodiálisis presentaban más frecuentemente trastornos metabólicos ( $12 \%$ vs $4 \%$ ). Los factores de riesgo para morir fueron la edad más temprana al iniciar la terapia con diálisis (azar ratio de 0.95 por cada inicio de terapia de más de 1 mes) y el que la causa de la insuficiencia renal crónica no fueran las anomalías congénitas (azar ratio ajustado de 1.49). El riesgo de mortalidad y probabilidades de trasplante fueron iguales en las dos terapias, mientras que los pacientes de hemodiálisis tenían un riesgo más alto de cambiar de técnica de diálisis (azar ratio ajustado de 1.64). 
Los autores señalan que el estudio tiene limitaciones como la falta de datos en el registro relacionados con la comorbilidad y concluyen que pese a la idea de que los bebes tienen que ser tratados con diálisis peritoneal, en Europa en el periodo estudiado, uno de cada ocho niños fue tratado con hemodiálisis. Por otra parte, las características de los pacientes al iniciar la terapia, las perspectivas de supervivencia y el tiempo que tardaron en trasplantarse fueron similares en ambos grupos.

\section{Haskin 0, Sutherland SM, Wong CJ. The Effect of Intradialytic Intralipid Therapy in Pediatric Hemodialysis Patients.J Ren Nutr.2016 Dec 3.:S1051- 2276(16)30154-6. doi: 10.1053/j.jrn.2016.10.003.}

Pese considerarse la mejor opción el trasplante, mientras este llega o no puede llevarse a cabo, como se ha visto en el artículo anterior, hay niños que se han de someter a técnicas dialíticas incluyendo la hemodiálisis, los problemas derivados de la técnica son frecuentes y también deben abordarse problemas metabólicos y de crecimiento, en general deficiente. Los suplementos nutricionales orales son la forma preferida para aumentar la nutrición; sin embargo, muchos niños tienen dificultades para tolerarlos por lo que se les puede ofrecer una terapia alternativa en forma de suplementos endovenosos durante la hemodiálisis.

Los autores del estudio administran en la unidad pediátrica emulsión de lípidos endovenosa como suplemento nutricional durante las sesiones de hemodiálisis y se plantearon evaluar la seguridad, eficacia y beneficios de esa terapia.

Participaron en el estudio 15 pacientes pediátricos en hemodiálisis que reciben emulsiones de lípidos endovenosas durante al menos 3 meses desde julio de 2011 hasta julio de 2014.

Se compararon antes y al final de esta etapa datos de laboratorio, medidas antropométricas y parámetros nutricionales. Se evaluó el peso seco, la altura, el índice de masa corporal y el índice de masa corporal corregido por edad-altura. Los parámetros nutricionales de laboratorio evaluados fueron: la albúmina, la tasa catabólica de proteína normalizada, el nitrógeno ureico en sangre prediálisis, la transferrina, el colesterol y los triglicéridos. También se registraron los eventos adversos durante la terapia.

Se observaron mejoras significativas en los niveles de albúmina, nitrógeno ureico en sangre prediálisis y tasa catabólica de proteína normalizada durante el trata- miento ( $\mathrm{P}=.02 ; \mathrm{P}=.03 ; \mathrm{P}=.03$, respectivamente). Seis pacientes $(37,5 \%)$ mejoraron su puntuación de la desviación estándar de peso, y ocho pacientes (50\%) mejoraron su puntuación de la desviación estándar de índice de masa corporal, aunque no fue estadísticamente significativa ( $P=.59 ; P=.9$, respectivamente). No se observaron efectos secundarios significativos.

A la vista de estos resultados las conclusiones de esta investigación son que la administración de emulsiones de lípidos endovenosas durante hemodiálisis es bien tolerada con efectos beneficiosos sobre los parámetros nutricionales. Es una terapia relativamente barata y con otras medidas de soporte nutricional puede ayudar a mejorar el estado nutricional de los pacientes pediátricos.

\section{Borzych-Duzalka D, Aki TF, Azocar M, White C, Harvey E, Mir S,et al (International Pediatric Peritoneal Dialysis Network (IPPN) Registry). Peritoneal Dialysis Access Revision in Children: Causes, Interventions, and Outcomes. Clin J Am Soc Nephrol. 2016 Nov 29.: CJN.05270516.}

Siendo la diálisis peritoneal la técnica dialítica de elección para los niños hay poca información respecto a los problemas que plantea el catéter peritoneal. Por tanto el objetivo de los autores de este trabajo fue evaluar en una población pediátrica la frecuencia, los factores de riesgo, las intervenciones y los resultados de cateter de diálisis peritoneal que habían necesitado una revisión quirúrgica. Participaron en este estudio 105 centros de nefrología pediátrica inscritos en el Registro Internacional de Pediatría Peritoneal. Se recogieron los datos de 824 pacientes incidentes y 1629 prevalentes y el periodo estudiado abarcó entre 2007 y 2015.

De una total de 2.453 pacientes, en 321 pacientes (13\%) se realizaron 452 revisiones de acceso lo que resulta 0.14 revisiones de catéter por año de tratamiento. De los 824 pacientes incidentes, necesitaron una revisión del catéter 186 (22.6\%), siendo la tasa de revisión de 0,17 revisiones por año de tratamiento ya que el $83 \%$ de las revisiones se produjeron durante el primer año de tratamiento con diálisis peritoneal. Las tasas de supervivencia del catéter en pacientes incidentes fueron $84 \%, 80 \%, 77 \%$ y $73 \%$ a los $12,24,36$ y 48 meses, respectivamente.

En el análisis de regresión logística multivariante, el riesgo de necesitar una revisión del acceso se asoció con las siguientes circunstancias: la edad más joven, diagnóstico de anomalías congénitas del riñón y del tracto urinario, ser portador de ostomías y ser portador 
de un catéter de túnel de cuello de cisne con porción intraperitoneal espiral (odds-ratio, 1.10; intervalo de confianza del 95\%, 1,02 a 1,19; $\mathrm{P}=0,01$ ). Las principales razones para las revisiones del acceso incluyen un mal funcionamiento mecánico $(60 \%)$, peritonitis (16\%), infección del sitio de salida (12\%) y fuga por el orificio de salida (6\%). La necesidad de reparar el de acceso aumenta el riesgo de no poder llevar a cabo la técnica o la muerte (cociente de riesgo, 1.35; $\mathrm{P}=$ 0.003). La disfunción del acceso debido a causas mecánicas duplicó el riesgo de fracaso de la técnica en comparación con causas infecciosas (cociente de riesgo, 1.95; $\mathrm{P}=0.03$ ).

La conclusión de este artículo es que las reparaciones del catéter de diálisis peritoneal son comunes en pacientes pediátricos sometidos a diálisis peritoneal y complican la realización de la técnica siendo necesario prestar atención a factores de riesgo potencialmente modificables.

Forbes TA, Shaw L, Quinlan C. Topical Honey in the Management of Pediatric Peritoneal Dialysis Exit Sites.Perit Dial Int. 2016 11-12;36(6):684-687.

Las directrices internacionales en la diálisis peritoneal abogan por regular la aplicación sistemática de mupirocina tópica crónica para el cuidado del orificio de salida del catéter puesto que hay evidencia que relaciona este tratamiento con una reducción de las tasas de infección $y$ de peritonitis. Sin embargo, algunos estudios recientes vinculan el uso de mupirocina con la aparición de resistencias e infecciones gram-negativas que ponen en duda la viabilidad a largo plazo de pomadas antibióticas como tratamiento profiláctico.

La miel preparada para uso clínico tiene un probado efecto antibacteriano y propiedades curativas de las heridas. Se han realizado ensayos controlados aleatorizados (el HONEYPOT prueba)*, sobre el uso de la miel para la prevención de la infección del orificio de salida del catéter peritoneal y de la peritonitis pero no se pueden extrapolar sus resultados al contexto pediátrico.

Con estos antecedentes los autores utilizaron un preparado de miel para uso clínico como coadyuvante para el cuidado del orificio de salida en 8 pacientes pediátricos con problemas como infección persistente o granuloma en dicho orificio. Ante unos resultados satisfactorios los autores de este trabajo afirman que en su institución se utiliza este producto y lo recomiendan como profiláctico puesto que puede facilitar la supervivencia del catéter en algunos pacientes y aunque no se haya realizado ningún estudio exclusivamente pediátrico se apoyan en su limitada experiencia y en la literatura que sugiere un efecto beneficioso en promover la curación de heridas infectadas con un menor riesgo de desarrollar resistencias a los antimicrobianos.

*Como ejemplo el estudio de Johnson DW, Clark C, Isbel NM, Hawley CM, Beller E, et al, titulado The honeypot study protocol: a randomized controlled trial of exit-site application of medihoney antibacterial wound gel for the prevention of catheter-associated infections in peritoneal dialysis patients, realizado en Australia sobre 372 pacientes adultos. Las conclusiones de este estudio afirman que la aplicación de miel es una buena estrategia profiláctica para evitar infecciones y reduce el riesgo de resistencias bacterianas.

Recibido: 3 febrero 2017

Revisado: 15 marzo 2017

Modificado: 20 marzo 2017

Aceptado: 30 marzo 2017

\section{Bibliografía}

1. Wedekin M, Ehrich JH, Offner G, Pape L. Renal replacement therapy in infants with chronic renal failure in the first year of life. Clin J Am Soc Nephrol 2010; 5:18-23. [Pubmed].

2. AAVV: Protocolos diagnósticos y terapéuticos en Nefrología Pediátrica Asociación Española de Nefrología Pediátrica, 3. a edición, 2014. www. aeped.es/protocolos/

3. AAVV. AENP Asociación Española de Nefrología Pediátrica. Nefrología Pediátrica. Manual Práctico. Panamericana 2011.

4. Frutos MA, Cabello M. Información a pacientes: cuándo y qué información suministrar. En: Guías S.E.N. Nefrologia 2010; 30(Supl 2):39-46.

5. Rheault MN, Rajpal J, Chavers B, Nevins TE. Outcomes of infants $<28$ days old treated with peritoneal dialysis for end-stage renal disease. Pediatr Nephrol 2009; 24:2035-9. 